\title{
STRATEGIC ISSUES IN TIME DIMENSION OF MARKETING TOOLS IN BUSINESS TO BUSINESS MARKETS
} R.K. Gopal* and T.V. Raju**

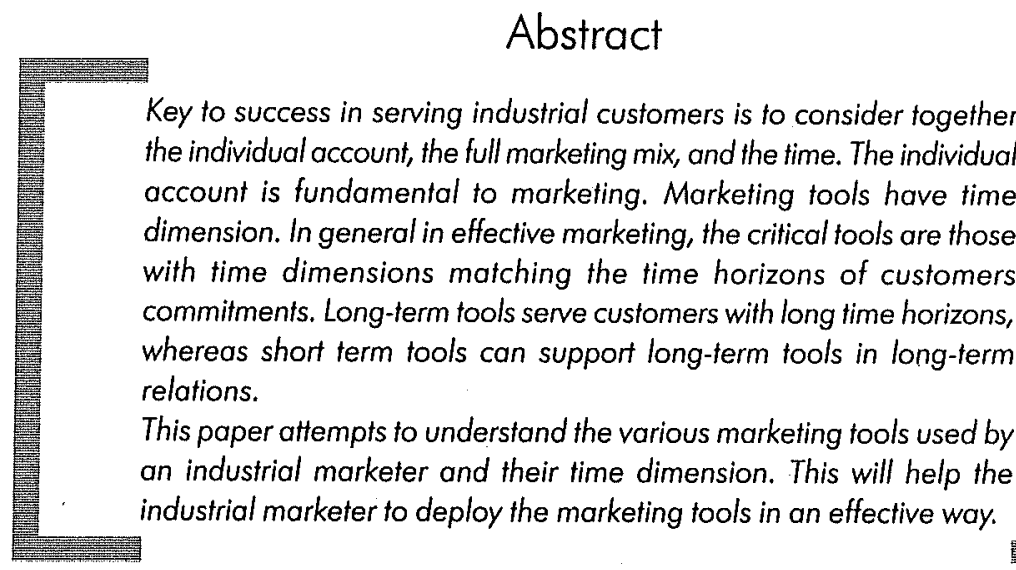

er

Although it might appear at first that marketers would essentially want to win an account early and stay in the account for a long term, it may become difficult for the marketer to achieve this, if the buyer's needs change significantly over a period of time. Accounts whose needs change significantly can require substantially different

* Faculty, Dept. of Management Studies, M.S. Ramaiah Instilute of Technology, Bangalore.

** Director, R.V. Instifute of Management Studies, Bangalore. 
marketing approaches at different times in their histories. It can be very difficult for the vendor to deploy a wide range of marketing tools, effectively and efficiently, to serve a range of customer needs. Problems of choosing and coordinating resources can become complicated when considered in the light of individual account histories.

The full marketing mix contains a wide variety of individual tools. It includes price (including payment terms and conditions), communications (including sales, advertising and public relations), channels of distribution (including logistical systems) \& product (widely defined to include design, engineering, and even the vendors general technological stance and direction).

The individual tools in the marketing mix have important characteristics in terms of time. Different marketing tools take different lengths of time to deploy. They also have effects of different durations. In general tools with especially long lasting effects also take long time to deploy. Shorter acting tools can be generally used more quickly. Therefore we can describe individual tools with single time descriptors, such as long-term tools, medium term tools and short-term tools.

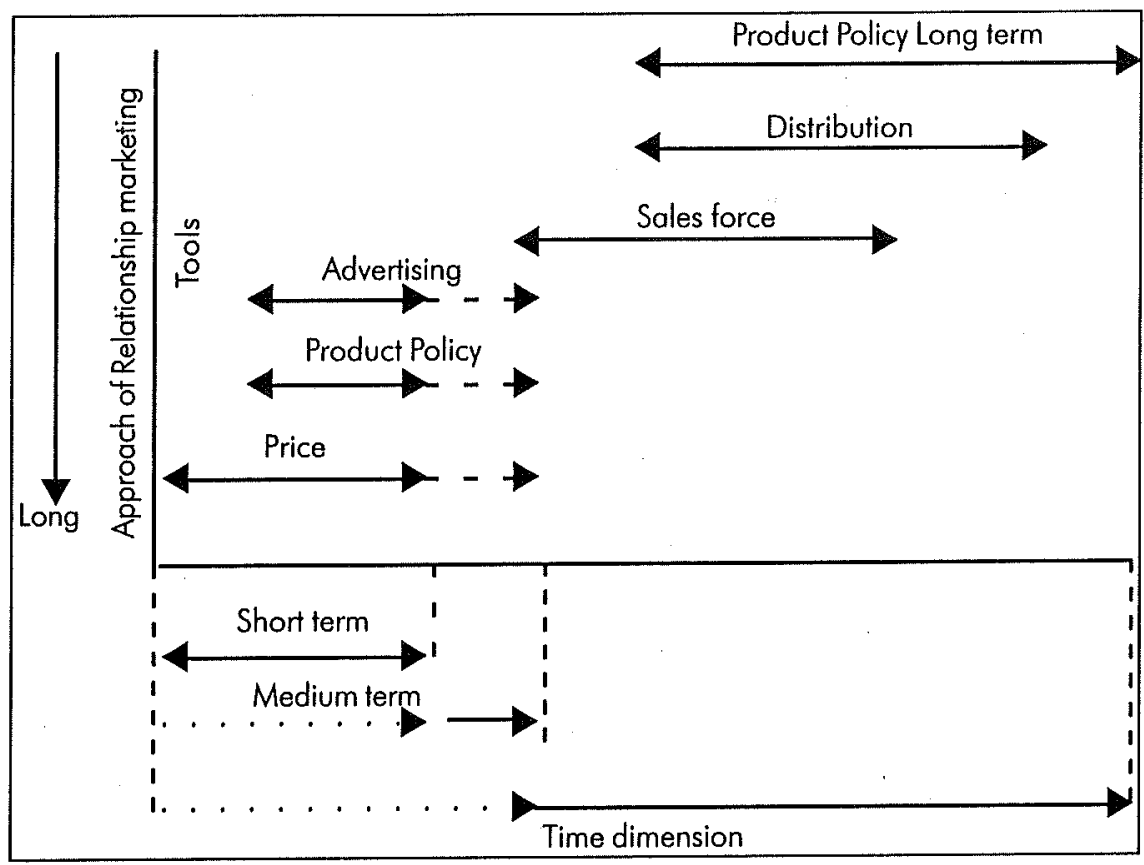

We can consider the five broad categories of tools: price, advertising, sales force, distribution and product for our analysis. These broad categories cover many but not certainly all-marketing tools. For example service as a separate tool apart from 
sales force and the basic business strategy as a tool is not considered here. The following model shows the range of time effects for each of five broad categories of tools.

\section{The Model for Time Dimension of Marketing Tools}

The above model indicates price, product policy, and advertising as the short to medium term tools, sales force and distribution as the medium to long-term tools and product policy (long term) as a long-term tool.

\section{a) Pricing policies as short to medium term tool:}

In setting prices, marketers of industrial products need to do the following:

1. Understand the total use of the product.

2. Analyse the benefit variable

3. Analyse the cost variable

4. Make cost benefit trade off

Although the first area is perhaps the most important, it is least easy to generalize about because, each application is so different. The marketer will have to study each and use. If the product is a raw material or component, it will be part of both the ultimate product and the process by which the product is made. If it is a piece of capital equipment, it is often a part of larger production system. If the product is a simple raw material price changes can be deployed depending upon the market conditions. Further, if it is a straight re-buy situation to the customer, price as a short-term tool is more effective. It can be easily deployed by perhaps printing a new price list, or perhaps by simply notifying sales people or price administrators of a new multiplier to be applied to an older price list, or by changing price rules or formulas.

If the product is a component part supplied to OEM customers, then price may act as a medium term tool. The OEM customers may not be very sensitive to price changes, because the OEM customers demand is a derived demand. The demand for the component parts depends on the ultimate demand of the product by the end users. For example, if an Automobile component manufacturer reduces the price of the component, the OEM Customer may not enhance his off take immediately. 
Unless the end market demand picks up he will not add to his inventory. In oligopoly markets, the price stability occurs due to Kinked demand concept. The marketer reduces the price only when he is able to do so because of the value engineering work associated with the reduction. The OEM customer also appreciates such moves by the marketer. In such cases price acts as a medium term tool.

\section{b) Product policies as a short to medium term tool:}

Relatively minor product changes are often short or at most medium term tools. They emphasize specific product features in their choices. Buyers will weigh the specific characteristics of the array of offerings available at the time of a choice. Minor product differences influence a specific decision, but, especially since they are not likely to induce or require strong vendor specific investment actions by the customer, the switching costs may be low and hence they are not likely to do much to discourage a change of vendor. In modified re-buy purchase situation, the out supplier may be considered if he offers some attractive minor product features. However, such product moves have rather short term effects. They can also usually be made rather quickly.

\section{c) Advertising as a short to medium term tool:}

Advertising in industrial markets is generally a short to medium term tool. In new task purchase situations and modified re-buy purchase situations, advertising in trade magazines helps to create awareness among the industrial users. Advertising tools can be deployed quickly when compared with long-term tools. Similarly advertising campaigns appear to have some effects that last beyond the actual end of the campaigns. However, it seems that advertisement effects do not last for truly long periods.

\section{d) Sales force as a medium to long-term tool:}

The sales force is usually medium to long-term tool. The sales force can create or facilitate smooth day to day working relationships between the two organizations by handling preorder, order to shipment, and post shipment services effectively. Sales force over a period of time develops lasting relationships with the customers. Especially for complex or technical products that must be adapted to the customer's particular situation the sales force can have medium term to long-term effects. In flow business and project business, the sales force may effectively act as a switching barrier by performing the following customer services effectively. 


\begin{tabular}{|c|c|c|c|}
\hline & Preorder & Order-to-shipment & Post shipment \\
\hline Flow Business & $\begin{array}{l}\text { - Accurate timely } \\
\text { quotations } \\
\text { - Knowledgeable } \\
\text { sales force }\end{array}$ & $\begin{array}{l}\text { - On time, complete, } \\
\text { accurate shipments } \\
\text { - Accurate, timely order } \\
\text { tracking / status } \\
\text { reports }\end{array}$ & $\begin{array}{l}\text { - Timely responsive } \\
\text { complaint resolution } \\
\text { - Quality, timely in } \\
\text { warranty \& out of } \\
\text { warranty services }\end{array}$ \\
\hline Project Business & $\begin{array}{l}\text { - Accessibility and } \\
\text { responsiveness of } \\
\text { personnel } \\
\text { - Quality, fimely } \\
\text { application and } \\
\text { support } \\
\text { - Product availability } \\
\text { information }\end{array}$ & $\begin{array}{l}\text { - Flexibility to react to } \\
\text { customer changes } \\
\text { to the order } \\
\text { - Experienced project } \\
\text { managers } \\
\text { - Ownership/authority } \\
\text { for multi product } \\
\text { department orders }\end{array}$ & $\begin{array}{l}\text { - Competent installation } \\
\text { support } \\
\text { - Accurate timely billing } \\
\text { - Effective spare parts } \\
\text { support }\end{array}$ \\
\hline
\end{tabular}

\section{e) Distribution channels as a long-term tool:}

Marketers and customers both have lasting relationships with the channel members. Selecting and maintaining the right kind of channel members is a challenging task to the industrial marketer. Depending on the product complexity and the size of the purchase the channel members may have to be selected. Investments in channel relationships usually pay back dividends to Vendor for long periods of time. The most important channel functions include product information, product customization, product quality assurance, lot size, assortment, availability, after sales service, and logistics. These aspects of distribution may have medium to long-term effects.

\section{F) Product policy as a long-term tool:}

The major changes in product design, technological stance, and technical capabilities are long-term tools. These take longer time to deploy but the effects are for a longer time. The development of a major new product that extends vendors offerings without a major change of direction frequently takes many years. The factors to be considered in new product development include strategic alignment, understanding users and customers needs, compliance issues, competitive analysis, product positioning, project priorities, risk management, market channels, management leadership, resource availability and dependency management. 
Short and medium term tools cannot alone win or maintain long-term commitments, however, these tools still have useful roles in long-term relationships. On the positive side they can provide important support for long-term tools. On the negative side, misuse of short and medium term tools severely damage long-term relationships.

\section{Conclusion}

The industrial marketers will generally benefit by addressing explicitly the issues of individual account, the marketing mix and the time. In relationship marketing they will benefit from adopting long time horizons in marketing strategies and from trying to anticipate market place changes so as to have enough time to make their own changes smoothly and consistently. In deploying marketing tools they will find it useful to think of deploying long-term tools and more account general tools first, and account specific tools can then be applied in coordinated support roles.

In transaction marketing the customer commitments will be short term and in such cases short term tools like price \& advertising may be deployed effectively.

\section{References:}

1. Industrial pricing to meet customer needs-Benson. P. Shapiro and Barbara B Jackson, Harvard business review 56, no 6, Nov-Dec 1978, pp 119-127

2. Designing channels of distribution - V.Kasturi rangan, Melvyn A.J. Menezes, and Ernie P. Maier.

3. Once more - How do you improve the customer service. 2 -By Frank V. Cespedes - Business horizons 35, No 2, March-April 1992, Indiana University, Graduate school of Business.

4. Winning and influencing industrial customers-The dynamics of customer relationshipsBarbara bund Jackson-Lexington publication

5. Industrial marketing by F.Robert Dwyer \& John F Tanner ir, Mc GrawHill international. 